\title{
Time-course of the Positive and Negative Affect Schedule (PANAS) during an episode of psychosis: a pilot study.
}

\author{
Trino Baptista ${ }^{1}$, Rosani Trinidad Colmenares ${ }^{2}$, Olga Janneth Vargas ${ }^{2}$, Javier Piñero ${ }^{2}$ \\ and Luis Rengel ${ }^{2}$ \\ ${ }^{1}$ Department of Physiology, Universidad de Los Andes Medical School, Mérida, \\ Venezuela. \\ ${ }^{2}$ Department of Psychiatry, Los Andes University Medical School, Mérida, Venezuela.
}

Key words: anxiety; depression; negative affect; positive affect; psychoses.

\begin{abstract}
A central issue in affective science is the assessment of specific feelings in severe mental disorders. The PANAS (Positive [PA] and Negative [NA] Affect Scale) is widely used, and we have described its psychometric properties in Venezuela. Here, the course of the PANAS is described during a psychotic episode requiring hospitalization. Eighteen consecutively admitted patients (56\% females) were assisted to answer the PANAS, the Brief Psychiatric Rating Scale (BPRS) and locally designed depression (GE-DEPRE) and anxiety (ANSILET) seales, at admission and at discharge. The PA subscale showed a non-significant increase $(\mathrm{p}=0.07)$, whereas the NA subscale displayed a significant decrease $(\mathrm{p}=0.01)$. In males, at discharge, the NA scale positively correlated with the ANSILET $(\mathrm{p}=0.09)$, whereas the PA inversely correlated with the GE-DEPRE scale $(\mathrm{p}=0.007)$. The PANAS may complement the standard psychological evaluations by monitoring specific affect dimensions, relatively independent from the core psychopathology.
\end{abstract}

Corresponding author: Trino Baptista. Department of Physiology, Universidad de Los Andes Medical School, Mérida, Venezuela. Email: trinobaptista@gmail.com 


\title{
Curso temporal de la Escala de Afectividad Positiva y Negativa (PANAS) durante un episodio de psicosis: estudio piloto.
}

\author{
Invest Clin 2020; 61 (4): 316-323
}

Palabras clave: ansiedad; afectivo negativo; afecto positivo; depresión; psicosis.

Resumen. Un elemento central en la ciencia del afecto es la evaluación de emociones específicas en trastornos mentales severos. La escala de afectividad positiva (AP) y negativa (AN), PANAS, se usa extensamente, y exploramos sus propiedades psicométricas en Venezuela. En este estudio describimos el curso de la PANAS durante un episodio de psicosis que requirió hospitalización. Dieciocho pacientes (56\% femeninas) admitidos consecutivamente fueron asistidos para responder, al ingreso y al eǵreso, la PANAS, la Escala Breve de Evaluación Psiquiátrica (BPRS), y escalas de depresión (GE-DEPRE) y ansiedad (ANSILET), diseñadas en Venezuela. La subescala de AP aumentó en forma marginalmente significativa $(\mathrm{p}=0,07)$, mientras que la subescala de AN disminuyó significativamente durante la hospitalización $(\mathrm{p}=0,01)$. Al egreso, sólo en los sujetos masculinos, la subescala de AN se correlacionó positivamente con la ANSILET $(\mathrm{p}=0,09)$, y la subescala de AP se correlacionó inversamente con la escala GE-DEPRE $(p=0,007)$. Los cambios en la PANAS no se correlacionaron con los cambios en la BPRS. El instrumento PANAS puede complementar las evaluaciones psicológicas usuales con el fin de monitorear dimensiones afectivas elementales, que son relativamente independientes de variables psicopatológicas.

Received: 22-07-2020 Accepted: 02-11-2020

\section{INTRODUCTION}

In the field of the so-called affective science, exploring the neurobiological and social basis of affect and emotions and their role in psychoeducation and treatment, are central issues. The positive and negative affect scale (PANAS) is a widely used instrument for affect evaluation (1). It is a self-administered interview, originally designed in English and translated to several languages. The PANAS is used in studies concerning basic neuroscience of affect, physical diseases, drug addictions, personality and mood disorders and psychoses, particularly schizophrenia (2-5). In these severe disorders, the
PANAS has been used in a diversity of studies such as the exploration of anhedonia $(6,7)$, ambivalence (8), hallucinations $(9,10)$, insight (11), tobaceo dependence (12) and psychoses liability (13-15).

Concerning affect in schizophrenia, studies have explored how patients experience and express emotions and the specific features of the corresponding physiological correlates (16). Specifically, these authors showed that people with schizophrenia displayed an overall dampened response during the anticipation of positive and negative stimuli, suggesting a general deficit in anticipatory emotional responses (17). Besides, Mote et al., (18) demonstrated that both

Vol. 61(4): 316 - 323, 2020 
women and men with schizophrenia exhibit fewer outward expressions but experience comparable emotion experience as people without that disease.

While the PANAS has been used in exploring affect in diverse psychotic disorders, few studies have used the PANAS in assessing the time-course of affect dimensions in subjects undergoing antipsychotic treatment due to a severe relapse (3).

We administered the PANAS during inpatient treatment for an acute psychotic episode, and correlated the PANAS scores with those of the Brief Psychiatric Rating Scale (BPRS) and of locally developed scales for depression (GE-DEPRE) and anxiety (ANSILET). The term "psychoses" encompasses a heterogenous group of mental disorders, each one possibly displaying specific combinations of affect disturbances. The purpose of this pilot, exploratory study, was aimed at testing whether the PANAS administration detects changes in affect in subjects with a severe psychotic relapse, irrespective of their primary mental disorder, and the direction of such changes throughout recovery. We expected to generate heuristic hypothesis for future studies with more homogenous clinical populations.

\section{METHOD}

The study was conducted in the inpatient psychiatric unit of Universidad de Los Andes Medical School, Mérida, Venezuela from January to July 2018. The Hospital's Ethics' Committee approved the protocol. This institute provides comprehensive treatment to patients with psychotic episodes for a maximum of three months. Patients mainly received pharmacological treatment and supportive psychotherapy and were discharged as soon as significant clinical improvement was achieved, and treatment was continued with outpatient protocols. The patients' relative in charge signed an informed consent authorizing the patient's participation.
Subjects: inclusion-exclusion criteria

Consecutively admitted female or male patients entered the study if they were: a) older than 18 years; b) diagnosed with a psychotic episode requiring antipsychotic medication, considering hallucinations and delusions as core features, regardless of their axis I, DSM-IV-R primary diagnosis; c) able to sustain a 10-20-minute interview, this one being the main reason to deny entering the protocol. Given the exploratory nature of this study, no further inclusion/exclusion criteria were used. The research team was not involved in treatment selection and duration, discharge timing and psychiatric diagnosis. Recruitment was stopped when the scheduled 6-month period to accomplish the study was completed.

\section{Procedure}

Each patient filled the research scales with the assistance of one of the authors, no more than one week after admission, and at discharge. Interviewers were trained to literally read the instructions and text, with minimal additional explanations.

\section{Scales}

The positive and negative affect scale (PANAS)

A 20-item version of the PANAS, validated in Venezuela by our group, was used. Similarly, to the original version (1), this version comprises 10 positive affect (PA) items and 10 negative affect (NA) ones.

The 20 items are rated on a severity scale ranging from 1 ("very slightly or not at all") to 5 ("extremely"). In this study, we used the "during the past week" and "in general" time-frame reference, that is, the instructions requested to rate the intensity of every emotion "in general, that is on the average" and "during the last week". The scales for depression (GE-DEPRE) (19) and anxiety (ANSILET) (20) were developed and validated in Venezuela and refer to an -in general- time frame reference. 
The 18-item BPRS is a clinician-administered scale that assesses psychotic and not psychotic symptoms occurring in the last days. It is rated with a $1-7$ scale, with $1=$ absent and $7=$ very severe (21).

\section{Statistical analysis}

Scales' scores at the beginning and the end of hospitalization were compared with the two-tailed $t$ test for related samples. Pearson correlation analysis was conducted between the scales. Results were considered significant when $\mathrm{p}<0.05$.

\section{RESULTS}

Eighteen consecutively admitted patients completed the study (Table I); all of them had been diagnosed with a DSMIV-R axis-I disorder for more than one year before current hospitalization. Given the small sample size, no analysis was conducted discriminating by diagnosis, besides psychosis. The average time of hospitalization was 27.7 \pm 13.1 days. The antipsychotic doses were risperidone (eight patients, $1.5-9 \mathrm{mg} /$ day), quetiapine (6 patients, $25-300 \mathrm{mg} /$ day) and olanzapine (4 patients, $10 \mathrm{mg} /$ day). All patients were on polypharmacy with any or more of the following agents: antidepressants, mood stabilizers or anxiolytics.

Negative significant correlations were observed between the PA and NA subscales only at discharge: total sample: -last-week- frame: $r$ $(18)=-0.69, \mathrm{p}=0.001$; females: -last weekframe: $\mathrm{r}(10)=-0.77, \mathrm{p}=0.009$; -in generalframe: $r(10)=-0.64, p=0.044$; males: -last week- frame: $r(8)=-0.6, p=0.09$.

No significant correlations were observed between the antipsychotic dose in olanzapine equivalents (22) and the PA and NA subscales during the last week at discharge ( $\mathrm{p}>0.05$, data not shown).

\section{Change in PANAS subscales}

In the whole sample, the PA subscale showed a small, non-significant increase during hospitalization (Fig. 1). The NA subscale

TABLE I

DEMOGRAPHIC AND GLINICAL FEATURES.

\begin{tabular}{|c|c|c|c|}
\hline & $\begin{array}{c}\text { Females } \\
(\mathrm{n}=10,56 \%)\end{array}$ & $\begin{array}{c}\text { Men } \\
(\mathrm{n}=8,44 \%)\end{array}$ & $\begin{array}{c}\text { Total } \\
(\mathrm{n}=18)\end{array}$ \\
\hline $\begin{array}{l}\text { Age } \\
\text { (years) }\end{array}$ & $43.4 \pm 13.4$ & $49.0 \pm 9.1$ & $45.9 \pm 11.7$ \\
\hline Days of hospitalization & $\begin{array}{l}26.3 \pm 8.4 \\
\text { Diagnosis }^{*}\end{array}$ & $29.4 \pm 17.9$ & $27.7 \pm 13.1$ \\
\hline $\begin{array}{l}\text { Schizophrenia } \\
\quad(295 . x x)\end{array}$ & 3 & 1 & 4 \\
\hline $\begin{array}{l}\text { Bipolar disorder } \\
\quad(296 . x x)\end{array}$ & 4 & - & 4 \\
\hline $\begin{array}{c}\text { Schizoaffective disorder } \\
(295.70)\end{array}$ & - & 2 & 2 \\
\hline $\begin{array}{c}\text { Other mood } \\
\text { disorder } \\
(296.90)\end{array}$ & 1 & - & 1 \\
\hline $\begin{array}{l}\text { Psychosis associated to } \\
\text { organic or medical condition** }\end{array}$ & 2 & 5 & 7 \\
\hline
\end{tabular}

Values represent average \pm standard deviation. *According to the DSM-IV-TR criteria. * Diagnostic codes: 292.12 , 293.83 and 293.9.

Vol. 61(4): 316 - 323, 2020 

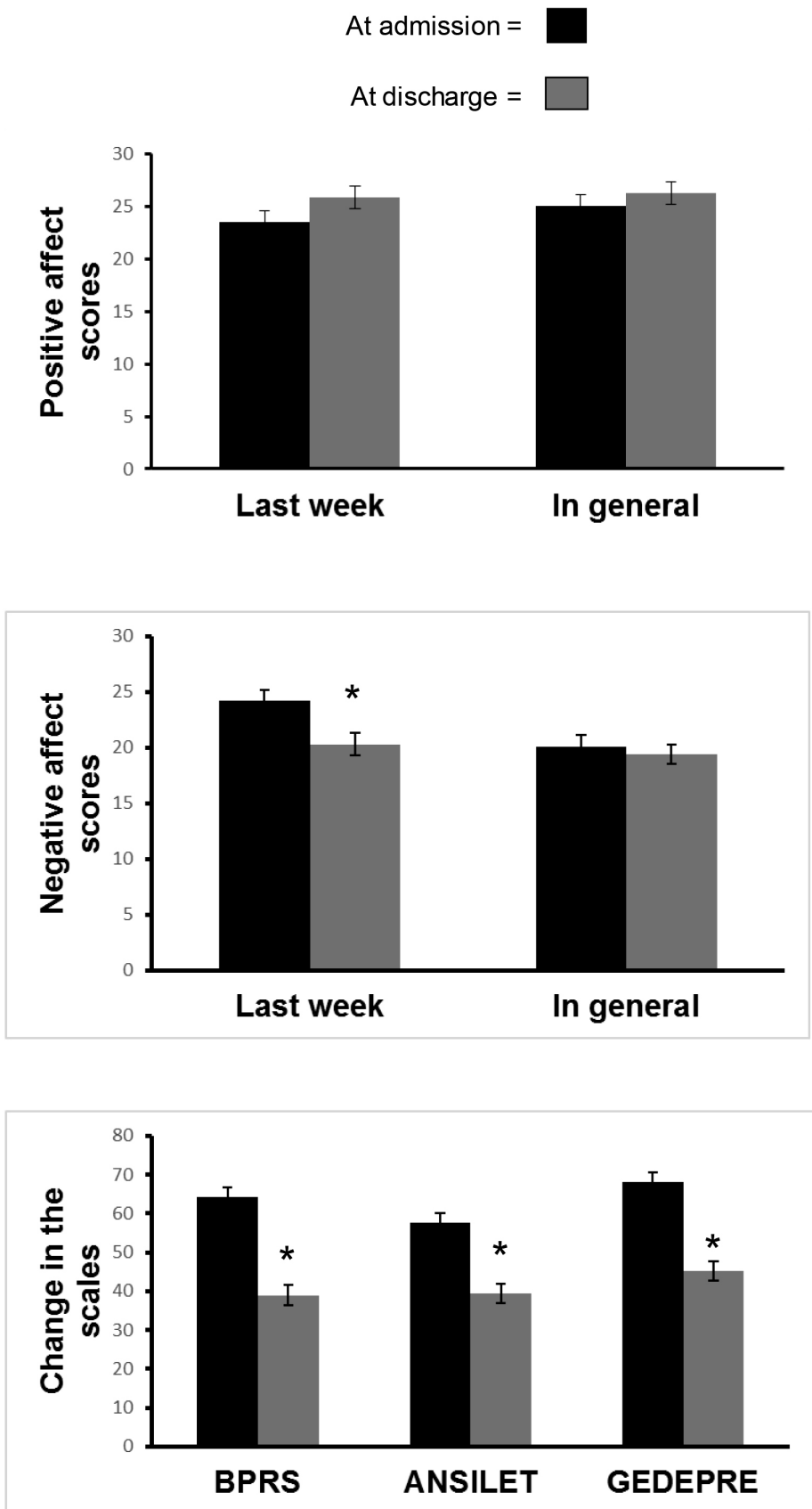

Fig. 1. Change in the scales during inpatient treatment.

-Last week- and -in general- correspond to the time frame of reference for the PANAS evaluation. Values represent average \pm standard error, for the two-tailed $t$ test for related samples. $\left.{ }^{*}\right)=$ significant differences.

PA: last week frame: $\mathrm{t}(17)=1.4, \mathrm{p}=0.18$; -in general- frame: $\mathrm{t}=1.9, \mathrm{p}=0.07$.

NA: last week frame: $\mathrm{t}=2.7, \mathrm{p}=0.015$; -in general- frame: $\mathrm{t}=0.9, \mathrm{p}=0.36$.

BPRS: $\mathrm{t}=7.1, \mathrm{p}=0.000$. ANSILET: $\mathrm{t}=6.1, \mathrm{p}=0.000 ;$ GEDEPRE $: \mathrm{t}=7.7, \mathrm{p}=0.000$. 
displayed a significant decrease only in the -during the last week- time frame (Fig. 1).

When discriminating by sex, males showed a marginally significant increase in PA during the -the last week- frame: $3.8 \pm$ 5.0 points, $\mathrm{t}(7)=2.1, \mathrm{p}=0.07$. Females displayed a marginally significant decrease in NA in both, last-week and generally timeframe: $-4.2 \pm 6.9$ and $-2.2 \pm 4.4$ points, $t$ (9) $=1.9$ and $1.8, \mathrm{p}=0.08$ and 0.09 , respectively.

\section{Correlation analysis}

Age did not correlate with the change in PA or NA during hospitalization, in the whole sample or when discriminating by sex ( $\mathrm{p}>0.05$, data not shown).

The PA and NA subseale change $(\Delta)$ and length of hospitalization showed significant positive correlations, as follows:

Total sample: $\Delta$ in NA-last week- frame: $\mathrm{r}(18)=0.67, \mathrm{p}=0.003$.

Females: $\Delta$ in NA -last week- frame: $r$ (10) $=0.64, \mathrm{p}=0.044$.

Males: $\Delta$ in $\mathrm{PA}$-in general- frame: $r$ $(8)=0.78, \mathrm{p}=0.022 ; \Delta$ in NA -last weekframe: $\mathrm{r}(8)=0.71, \mathrm{p}=0.049$.

Hence, the longer the hospitalization time, the higher the increase in PA and the decrease in NA. When evaluating data of individual patients, the highest NA improvement (decrease in scores) was observed in a short period, particularly in subjects with Organic Mental Disorders with prominent affective symptoms.

Change in BPRS, depression and anxiety scales; correlations with the change in the PANAS

All the psychopathology seales displayed a significant decrease during hospitalization, in the whole sample and when discriminating by sex (Fig. 1).

The $\Delta$ in the PA and NA subseales did not significantly correlate with the $\Delta$ in any of the psychopathology scales, neither in the whole sample, nor when discriminating by sex ( $p>0.05$, data not shown).
The PA and NA subscale scores did not correlate with any of the psychopathology scale scores in the whole sample. However, in males, the NA at discharge positively correlated with the ANSILET scores: -last week- frame: $\mathrm{r}(8)=0.63, \mathrm{p}=0.09$; -in general- frame: $r=0.89, p=0.003$. In males too, the PA subscale negatively correlated with the GEDEPRE scale at discharge: -last week- frame: $r=-0.8, p=0.007$; -in generalframe: $r=-0.63, p=0.09$.

\section{DISCUSSION}

This study assessed the PANAS scores during hospitalization in patients with a severe psychotic episode. The small sample size precluded analysis according to the specific mental disorder; hence, results will be discussed in the context of psychotic episodes in general. Most studies have been conducted in subjects with schizophrenia not in severe relapses $(3,8,9-13,16-18)$.

We observed moderate inverse correlations between the PA and NA subscales (-0.55 to -0.77) and obtained similar findings in healthy volunteers in the PANAS validation study. In the PANAS original study, the correlation values were low (-0.12 to -0.23$)$ (1).

These results are of academic and practical relevance. The NA improved more and faster than PA; only males displayed a small non-significant increase in PA. These results suggest that more robust strategies are needed to improve PA during a psychotic episode, particularly in women, and not only to focus in reducing NA. In any ease, length of hospitalization positively correlated with improvement in both affeet dimensions.

A robust correlation between the PANAS and the psychopathology seales was not observed, neither in specific time-points nor in the change along treatment. Only in males at discharge, a positive correlation between PA and the anxiety scale was observed, and a negative correlation between the PA dimension and the depression scale. These results confirm that the PANAS dimensions 
are relatively independent from the depression, anxiety, and psychosis constructs, and support the contention of a specific value in themselves for the assistance and emotional growth in subjects with serious mental disorders.

\section{CONCLUSIONS AND LIMITATIONS}

We confirmed that the PANAS detects changes in elemental emotions in patients during a relapse episode of psychoses, which required inpatient treatment and intensive antipsychotic medication. Importantly enough, the negative emotions improved more than the positives particularly in women, and the opposite was observed in men, despite significant decrements in anxiety, depression, and psychoses indicators. This suggests that mental health teams must optimize pharmacological and non-pharmacological interventions to stimulate positive emotions, and not only decrease the negative ones.

These preliminary results have several limitations. The sample size was small and heterogeneous. Hence, this study waits for replication in protocols with bigger samples allowing the assessment of specific disorders, types of antipsychotics, diverse treatment lengths and more frequent timepoints of evaluation besides admission and discharge. These limitations preclude the generalization of our results and must be considered for future studies. Specifically, it must be clarified whether the relatively small improvement in positive emotions is commonly observed in many or all psychoses relapse episodes, or if a different profile may be observed in discrete mental illnesses such as schizophrenia and mood disorders.

\section{ACKNOWLEDGMENTS}

This study was the Thesis of Dr. R.T. Colmenares to obtain her tittle of Specialist in Psychiatry, at Universidad de Los Andes, Mérida, Venezuela.

\section{REFERENCES}

1. Watson D, Clark LA, Tellegen A. Development and validation of brief measures of positive and negative affect: the PANAS scales. J Pers Soc Psychol 1988; 54: 1063-1070.

2. Díaz-García A, González-Robles, Mor S, Mira A, Soledad Quero A, García-Palacios A, Baños RM, Botella C. Positive and Negative Affect Schedule (PANAS): psychometric properties of the online Spanish version in a clinical sample with emotional disorders. BMC Psychiatry 2020; 20:56. Doi. org/10.1186/s12888-020-2472-1.

3. Mohn C, Olsson AK, Helldin L. Positive and negative affect in schizophrenia spectrum disorders: A forgotten dimension? Psychiatry Res $2018 ; 267: 148-153$. Doi: 10.1016/j. psychres.2018.05.060.

4. Kim BN, Kwon SM. The link between hypomania risk and creativity: The role of heightened behavioral activation system (BAS) sensitivity. J Affect Disord 2017; 215: 9-14. Doi: 10.1016/j.jad.2017.02.033.

5. Reinke B, van de Ven V, Matura S, Linden DEJ, Oertel-Knöchel V. Altered intrinsic functional connectivity in language-related brain regions in association with verbal memory performance in euthymic bipolar patients. Brain Sci 2013; 3: 1357-1373; Doi:10.3390/brainsci3031357.

6. Horan WP, Kring AM, Blanchard JJ. Anhedonia in Schizophrenia: A review of assessment strategies. Schiz. Bull 2006; 32: 259-273. Doi:10.1093/schbul/sbj009.

7. Karcher NR, Martin EA, Kerns JG. Examining associations between psychosis risk, social anhedonia, and performance of striatum-related behavioral tasks. J Abnorm Psychol 2015; 124: 507-518. Doi:10.1037/ abn0000067.

8. Docherty AR, Sponheim SR, Kerns JG. Further examination of ambivalence in relation to the schizophrenia-spectrum. Schizophr Res 2014; 158: 261-263. Doi: 10.1016/j.schres.2014.06.015.

9. Dyck MS, Mathiak KA, Bergert S, Sarkheil P, Koush Y, Alawi EM, Zvyagintsev M, Gaebler AJ, Shergoill SS, Mathiak K. Targeting treatment-resistant auditory verbal hallucinations in schizophrenia with fMRI-based neurofeedback - exploring different cases 
of schizophrenia. Front Psychiatry 2016; 7 : 37. Doi: 10.3389/fpsyt.2016.00037.

10. Bais L, Vereammen A, Stewart R, van Es F, Visser B, Aleman A, Knegtering H. Shortand long-term effects of left and bilateral repetitive transcranial magnetic stimulation in schizophrenia patients with auditory verbal hallucinations: a randomized controlled trial. PLoS One 2014; 9: e108828. Doi: 10.1371/journal.pone.

11. Larabia DI, van der Meerb L, Pijnenborgd, GHM, Ćurčić-Blakea B, Aleman A. Insight and emotion regulation in schizophrenia: $\mathrm{A}$ brain activation and functional connectivity study. NeuroImage Clin 2018; 20: 762-771.

12. Williams JM, Steinberg ML, Zimmermann MH, Gandhi KK, Stipelman B, Ziedonis DM. Comparison of two intensities of tobacco dependence counseling in schizophrenia and schizoaffective disorder. J Subst Abuse Treat 2010; 38: 384-393. Doi:10.1016/j. jsat.2010.03.006.

13. Cordes JS, Mathiak KA, Dyck M, Alawi EM, Gaber TJ, Zepf FD, Klasen M, Zvyagintsev M, Gur RC, Mathiak K. Cognitive and neural strategies during control of the anterior cingulate cortex by fMRI neurofeedback in patients with schizophrenia. Front. Behav. Neurosei 2015; 9: 169. Doi: 10.3389/fnbeh.2015.00169.

14. Fonseca-Pedrero E, Ortuño-Sierra J, Inchausti F, Rodríguez-Testal JF, Debbané M. Beyond clinical high-risk state for psychosis: The network structure of multidimensional psychosis liability in adolescents. Front Psychiatry 10:967. Doi: 10.3389/fpsyt.2019.00967.
15. van der Velde $\mathbf{J}$, Opmeer EM, Liemburg EJ, Bruggeman $\mathbf{R}$, Nieboer $\mathbf{R}$, Wunderink $\mathbf{L}$, Aleman A. Lower prefrontal activation during emotion regulation in subjects at ultrahigh risk for psychosis: an fMRI-study. NPJ Schizop 2015; 1: 15026; Doi:10.1038/npjschะ.2015.26.

16. Kring AM, Moran EK. Emotional response deficits in schizophrenia: insights from affective science. Schiz Bull 2008; 34: 819834. Doi:10.1093/schbul/sbn071.

17. Moran Ek, Kring AM. Anticipatory emotion in schizophrenia. Clin Psychol Sci 2018; 6: 63-75. D oi:10.1177/2167702617730877.

18. Mote J, Stuart BK, Kring AM. Diminished emotion expressivity but not experience. in men and women with schizophrenia. $J$ Abnorm Psychol $2014 ; 123$ : 796-801. Doi: 10.1037/abn0000006.

19. Escalante G. Escala para medir Depresión. Estudio Téenico. Centro de Investigaciones Psicológicas, Universidad de los Andes (ULA); Mérida-Venezuela, 2005.http://www. saber.ula.ve/handle/123456789/14719. Recuperado el 24-10-2020.

20. Esqueda L. Escala para medir Ansiedad. Estudio Técnico. Centro de Investigaciones Psicológicas, Universidad de los Andes (ULA); Mérida-Venezuela, 1990. http://www.saber. ula.ve/handle/123456789/14719. Recuperado el 24-10-2020.

21. Overall JE, Gorham DR. The Brief Psychiatric Rating Scale. Psychol Rep 1962; 10: 799-812.

22. Leucht S, Samara M, Heres S, Davis JM. Dose equivalents for antipsychotic drugs: The DDD method. Schiz Bull 2016; 42 (Sup 1): S90-S94. Doi:10.1093/schbul/sbv167. 